UHERO

THE ECONOMIC RESEARCH ORGANIZATION AT THE UNIVERSITY OF HAWAI'I

\section{A DYNAMIC APPROACH TO PES PRICING AND FINANCE FOR INTERLINKED ECOSYSTEM SERVICES: WATERSHED CONSERVATION AND GROUNDWATER MANAGEMENT}

BY

JAMES ROUMASSET AND CHRISTOPHER WADA

Working Paper No. 2012-7

October 2012 


\title{
A dynamic approach to PES pricing and finance for interlinked ecosystem services: Watershed conservation and groundwater management
}

\author{
James Roumasset* \\ University of Hawaii at Manoa \\ \& University of Hawaii Economic Research Organization \\ Christopher Wada ${ }^{\dagger+}$ \\ University of Hawaii Economic Research Organization
}

October 19, 2012

\begin{abstract}
A theory of payment for ecosystem services (PES) pricing consistent with dynamic efficiency and sustainable income requires optimized shadow prices. Since ecosystem services are generally interdependent, this requires joint optimization across multiple resource stocks. We develop such a theory in the context of watershed conservation and groundwater extraction. The optimal program can be implemented with a decentralized system of ecosystem payments to private watershed landowners, financed by efficiency prices of groundwater set by a public utility. The theory is extended to cases where land is publicly owned, conservation instruments exhibit non-convexities on private land, or the size of a conservation project is exogenous. In these cases, conservation investment can be financed from benefit taxation of groundwater consumers. While volumetric conservation surcharges induce inefficient water use, a dynamic lump-sum tax finances investment without distorting incentives. Since the optimal level of conservation is generated as long as payments are correct at the margin, any surplus can be returned to consumers through appropriate block pricing. The present value gain in consumer surplus generated by the conservation-induced reduction in groundwater scarcity serves as a lower bound to the benefits of conservation without explicit measurement of other benefits such as recreation, biodiversity, and cultural values.
\end{abstract}

Keywords: Renewable resources, dynamic optimization, groundwater management, watershed conservation, payments for ecosystem services, benefit taxation, conservation surcharge

JEL codes: Q25, Q28, H2

\footnotetext{
* Professor, Department of Economics; Research Fellow, University of Hawaii Economic Research Organization; E-mail: jimr@hawaii.edu.

${ }^{\dagger}$ Postdoctoral Researcher; E-mail: cawada@hawaii.edu; Tel: (808) 956-2325; Fax: (808) 956-4347.

* Corresponding author.
} 


\section{Introduction}

Paying for ecosystem services has advanced as a method for incentivizing continued or increased provision by private landowners (Daily et al., 2009). Typically a price to be paid for each unit of the service is reckoned exogenously. Payments are sometimes set in accordance with a metric unrelated to the value of the services provided, e.g. the perceived opportunity costs of upstream landowners (Muñoz-Piña et al., 2008). In other instances, the value can be approximated exogenously under a "small project" assumption. For example, the additional carbon sequestration from a forest may have a negligible impact on the marginal damage cost of atmospheric carbon (Pearce, 2001). However, many other services - e.g., improvements to water quality, contributions to ecotourism, nutrient provision to a fishery - have a more localized value. In such cases, the marginal values must be derived. Inasmuch as an ecosystem is characterized by interacting resources, solving for these marginal values entails joint optimization.

If the ecosystem service prices are exogenously determined, private providers can be properly incentivized by payments according to the fixed Pigouvian subsidy (Baumol and Oates, 1988). For public conservation projects, the exogenous price is used to compare whether the benefits of enhancing the supply of ecosystem services warrant expending the necessary costs. In more conceptual expositions, the payment for a positive externality is treated analogously to a Pigouvian tax for a negative externality. The underlying idea is that if we can determine the marginal cost of producing the environmental benefit and the marginal benefit to the recipients, the appropriate ecosystem payment is where marginal benefits equal marginal costs (Engel et al. 2008). 
Suppose, however, that the ecosystem service in question provides indirect benefits via another natural resource. Then, the marginal benefit of the ecosystem service is only revealed as part of the conservation and use decisions, which should be jointly determined. For example, the value of groundwater recharge provided by a watershed depends on both the quantity of groundwater extraction and the amount of watershed conservation. This requires solving for the dynamic management of two interacting resources. The solution to the dynamic optimization problem confirms that the marginal benefit of the ecosystem service is determined by the shadow price of the downstream resource, i.e. the price of the ecosystem service is endogenous to the model. We show that the socially optimal provision of the ecosystem service can be achieved in a decentralized framework, wherein land is privately owned and groundwater is managed by a public utility, as long as the ecosystem payments are set according to the shadow price of the service and groundwater is priced at its marginal opportunity cost.

Previous studies have taken a similar "production function approach" to endogenizing the value of ecosystem services, wherein the service provided by the upstream resource serves as an input to the production of the consumed downstream resource (Sathirathai and Barbier, 2001). However, one of the resources is typically taken as open access, and dynamic considerations are limited to changes in the steady-state equilibrium (Barbier et al., 2002). Barbier (2007) develops a framework amenable to analyzing transitional dynamics but focuses on the numerical estimation of ecological and economic parameters in the governing equations. Sanchirico and Springborn (2011) derive a PES equation in the context of a mangrove-fishery ecosystem and provide a pioneering numerical solution to the complex multiple-resource problem. However, their 
primary focus is on integrating economic optimization principles into ecosystem management, and they do not discuss in detail methods for financing ecosystem payments. We solve for the shadow prices of the dynamic system using more generalized (unparameterized) ecosystem and economic functions, which we believe allows for clearer interpretation, as well as discuss what the solution implies for ecosystem prices and financing ecosystem payments.

Without a viable scheme of finance, PES proposals may fall victim to budget exigencies, especially in hard fiscal times. And depending on finance, PES programs may redistribute income in a manner that is undesirable from an equity standpoint. To avoid these problems, we suggest how PES schemes can be financed through intergenerational benefit taxation. Given that our objective is to maximize the present value of an infinite stream of net benefits, optimal ecosystem payments may be relatively large for current generations, while much of the benefits are enjoyed by future generations. Financing watershed conservation with general revenue may therefore require earlier generations to shoulder the burden of sustainability, even though the benefits accrue primarily to the future. Inasmuch as future generations do not vote, this may be politically untenable. In the name of feasibility, we develop a mechanism, wherein conservation investment is financed from proportional benefit taxation of current and future groundwater users. ${ }^{1}$ While volumetric conservation surcharges ${ }^{2}$ induce inefficient water use, a lump-sum tax fully finances conservation investment while preserving efficient incentives. Since the

\footnotetext{
${ }^{1}$ Benefit taxation also satisfies distributional equity in the sense of "just taxation" as described by Wicksell (1958) and Lindahl (1958). Proportional benefit taxation is discussed further in section 4.1.

${ }^{2}$ In the context of public utilities, a conservation surcharge is generally understood to be a volumetric charge that integrates marginal and average costs in price structure design (see e.g. Mann and Clark, 1993). The charge is determined according to the avoided-cost principle, and demand-side conservation is induced by incorporating capacity expansion costs into the price for discretionary usage. This type of conservation surcharge may be roughly correct for electric utilities, but since groundwater is a renewable resource, the optimal pricing structure for water should include marginal user cost.
} 
optimal level of conservation is generated as long as the payments are correct at the margin, any surplus can be returned to consumers through an appropriate block pricing structure. Our main theoretical results remain valid, even when land is publicly owned, conservation instruments exhibit non-convexities on private land, or the size of a conservation project is determined exogenously by policymakers.

In the next section, we review some of the recent developments in PES theory and practice. We then provide a rigorous framework to analyze general concepts that underlie current PES programs but have remained fairly informal to date. A model is developed to jointly optimize extraction and consumption of a downstream resource (groundwater) and investment in the conservation of an upstream service-providing resource (watershed). While the model is motivated by a specific example, the framework - which includes stock-dependent extraction costs and a stock-dependent net growth function - is generally applicable to other unidirectional resource linkages. We find that optimal management is driven by an extended Hotelling condition for the extraction of groundwater and an equimarginality condition for natural capital, reminiscent of Jorgensen (1963), which states that capital should be accumulated until its marginal value is equal to its implicit rental price. The shadow price of recharge emerges from the solution of these first order conditions and informs optimal ecosystem payments. Section 4 describes a mechanism for financing optimal watershed conservation, wherein downstream beneficiaries are taxed according to their potential benefits, and efficient incentives are maintained for both upstream and downstream management. Lastly, we discuss the management implications of a secular decline in groundwater recharge due to climate change. Conservation investment depresses the shadow price of groundwater and 
increases welfare, which means that the need for investment is amplified by declining recharge. The excess burden of ignoring the watershed increases, even if groundwater extraction is optimized independently.

\section{PES in theory and practice}

The Millennium Ecosystem Assessment (2005) defines ecosystem services as "the benefits people obtain from ecosystems," which suggests that groundwater recharge can be viewed as an ecosystem service provided by a watershed to downstream water users. When land in the upper watershed is privately owned, desired conservation objectives can theoretically be achieved through payments for ecosystem services (PES), which are "voluntary transactions where a well-defined environmental service is being bought by a service buyer from a service provider if and only if the service provider secures service provision" (Engel et al., 2008). Much of the recent work on ecosystem services has focused on valuation techniques, modeling complicated natural linkages between multiple ecosystems, and equity considerations (e.g. Carpenter et al., 2009; Costanza et al., 1997; Daily, 1997; Daily et al., 2000; Daily et al., 2009; Mendoza et al., 2011; Turner and Daily, 2008). ${ }^{3}$ While most researchers appear to be in agreement that beneficiaries should at least be partially responsible for financing payments, the economic foundations underlying many PES programs remain largely informal and leave open important questions, such as how payments should be precisely determined and how conservation investment should be financed without distorting incentives. In developing a framework

\footnotetext{
${ }^{3}$ The work by Mendoza et al. (2011) uses a dynamic framework to solve for stream diversion and the endogenous shadow price of water for known downstream benefit functions such as for agriculture and hydropower. One of the main objectives of our paper is to highlight the importance of managing both the upstream and downstream stocks simultaneously in a theory of PES pricing and finance.
} 
to address some of these questions, we take a systems approach, as is often emphasized in sustainability science (e.g. Roumasset et al., 2010; Kareiva et al., 2011). We develop a dynamic watershed-groundwater model and derive the optimal trajectories of groundwater extraction and investment in watershed conservation. In addition, an optimality condition is derived to measure the value of groundwater recharge, the ecosystem service of interest.

PES programs are typically aimed at individual private landowners, but service users are often lumped together, with the government or a public utility responsible for the details of financing the program. A common way to finance payments for ecosystem services is to use general revenue. For example, in China, the government has invested billions of dollars in its conservation program (Liu et al., 2008); and Costa Rica funds its PES program through a national gasoline tax, World Bank lending, and a conservation fee for water users (Pagiola, 2008). This source of financing has the disadvantage that increasing required tax revenues generates additional marginal excess burden (Ballard et al., 1985).

A commonly employed alternative to financing from general revenue is a volumetric tax on downstream beneficiaries. Examples of potentially distorting user fees or surcharges can be found in several watershed conservation programs throughout North America. Mexico's PES program is financed by earmarked water user fees totaling $\$ 18.2$ million annually (Pagiola et al., 2005); Houston (Texas) incorporates dedicated conservation fees into the existing water rate structure; Salt Lake City (Utah) finances its Watershed-Water Rights Purchase Fund by a $\$ 0.50$ surcharge on each monthly water bill; Rhode Island funds its Watershed Land Acquisition Program with a volumetric surcharge 
of $\$ 0.01$ per hundred gallons of water consumed; and New York City's Catskills watershed management plan is being financed by bonds, the federal, state, and local governments, as well as a $9 \%$ increase in the taxes on water bills over a five year period. Although all of the programs target beneficiaries in the spirit of PES and successfully generate revenue (e.g. \$2.2 million annually in Rhode Island), they are not welfare maximizing because user fees drive a wedge between marginal benefits and costs.

Neither financing out of general funds nor out of user fees takes into account joint resource optimization. Yet, financing projects for ecosystem service provision should be informed by how both the service-providing resource and the downstream resource are managed. In particular, the proposed finance mechanism should account for the fact that benefits of investment in the provision of ecosystem services vary over time. Moreover, charges can be levied in a manner that does not distort incentives for downstream resource users. Specifically, we show in the current paper that total welfare, measured in net present value terms, can be increased by replacing volumetric surcharges (i.e. charges based on the amount of water consumption) with lump-sum proportional benefit taxes.

While the concept of incentivizing ecosystem service provision with direct payments from beneficiaries is attractive, the applicability of the framework currently developed in the literature is arguably limited. First, standard PES programs may be useful for the provision of services such as carbon sequestration, where prices of carbon may be estimated exogenously, but the value of services generated by a watershed generally depends on downstream resource extraction and upstream conservation 
simultaneously. ${ }^{4}$ Thus, a joint optimization model is required to determine the payment necessary to generate the optimal watershed conservation profile. In addition, many existing models are either static by theoretical design (e.g. Ferraro and Simpson, 2002) or implicitly static because the underlying valuation methods for the ecosystem services (e.g. Farber et al., 2002) are applied to a single point in time. To address these issues, we develop a dynamic resource optimization model and a mechanism to finance the optimal provision of an ecosystem service.

To complicate matters, the quality of watersheds in many regions is in decline due to urban development, invasive species, logging, recreation, or other activities that use the watershed, and climate change may exacerbate (or ameliorate) the problem (World Bank, 2004; WWAP, 2009). Traditional water economics studies that recommend marginal cost pricing to induce demand-side conservation and take groundwater inflow or recharge as constant (e.g. Feinerman and Knapp, 1983; Gisser and Sanchez, 1980; Koundouri, 2004; Pitafi and Roumasset, 2009), therefore, need to be modified to account for the possibility of declining recharge. We discuss how integrated groundwaterwatershed management provides adaptation to climate change.

\section{Optimal watershed conservation and groundwater extraction}

Inasmuch as watershed conservation reforms and groundwater management reforms should be implemented simultaneously to maximize societal welfare, we develop a model to address the problem of jointly managing a watershed and a coastal groundwater aquifer. A coastal aquifer is a generalized version of an inland aquifer that

\footnotetext{
${ }^{4}$ Using a stochastic control framework, Batabyal et al. (2003) solve for the scarcity value of an ecosystem service, which they define as the probability that the provision of the service is jeopardized. However, they do not provide a means of converting the probability to a monetary value.
} 
includes the possibility of leakage outside of the system. Mathematically the inland aquifer can be represented by suppressing the leakage term $(L)$, in the maximization problem (1).

\subsection{Description of the system}

The volume of groundwater stored in a coastal aquifer depends on the aquifer boundaries, lens geometry, and rock porosity (Mink, 1980). Groundwater economics models typically use the head level, or the vertical distance between mean sea level and the top of the freshwater lens, as an index for the volume of stored groundwater. To maintain congruence with a more general resource economics theory, however, we express the volume simply as a stock variable $(X)$. Following Krulce et al. (1997), the stock trajectory is governed by natural recharge $(R)$, leakage $(L)$, and extraction $(q)$. Although specific to groundwater resources, recharge (net of leakage) can be viewed more generally as a stock-dependent growth function, which is characteristic of many other renewable resources. Thus while the model is motivated by a specific example, the methodology is transferable to other unidirectional linkages between renewable resources.

As the volume of stored groundwater declines, the distance water must be lifted increases and consequently extraction cost rises, i.e. $c_{q}^{\prime}\left(X_{t}\right)<0$. Wells nearest the coast face salt-water intrusion soonest as the lens of freshwater shrinks due to extraction, and costs rise further as extraction is shifted toward deeper inland wells which require more energy to obtain water. Thus, the cost function is assumed to be convex but not strictly 
so, i.e. $c_{q}^{\prime \prime}\left(X_{t}\right) \geq 0 .^{5}$ While in theory, brackish water could continue to be pumped from

salinized wells and treated to potable standards, we assume that the savings from desalinating brackish feed water (as opposed to saltwater) do not warrant the extra pumping costs. Leakage is also a function of stock when low-permeability deposits of sediments build up aquifer pressure and constrain submarine groundwater discharge. Pressure from the lens causes some freshwater to discharge via coastal springs or subterraneously into the ocean. As the stock declines, leakage decreases both because of the smaller surface area along the ocean boundary and because of the decrease in pressure due to the shrinking of the lens. Thus $L^{\prime}\left(X_{t}\right)>0$ and $L^{\prime \prime}\left(X_{t}\right) \geq 0$. Because it occurs over the surface area of the lens, leakage continues, even when wells nearest the coast begin to face salinization.

Natural groundwater recharge is assumed to be an increasing and concave function of the conservation capital stock $(N),{ }^{6}$ which satisfies the Inada conditions, i.e. $\partial R / \partial N_{t}>0, \partial^{2} R / \partial N_{t}^{2}<0, \lim _{N_{t} \rightarrow 0} R^{\prime}\left(N_{t}\right)=\infty$ and $\lim _{N_{t} \rightarrow \infty} R^{\prime}\left(N_{t}\right)=0 .{ }^{7}$ If investment expenditures are optimally allocated amongst available conservation instruments, then it follows that the first units of capital are most effective at enhancing recharge and that the marginal product of capital eventually tapers off. Although conservation capital is

\footnotetext{
${ }^{5}$ In certain instances, e.g. when some wells are owned by the public utility and others are owned privately, the public utility may be prohibited from extracting in such a way that would compromise the quality of water pumped from private wells. In that case, new wells may be drilled, which would increase the costs non-linearly. However, the assumption of non-strict rather than strict convexity includes the possibility of linear extraction costs. If the current infrastructure is sufficient to meet future demand, then the physical cost of withdrawal is determined entirely by the energy costs required to lift the water.

${ }^{6}$ Alternatively, one could model recharge directly as a function of investment expenditures (Kaiser and Roumasset, 2002).

${ }^{7}$ Recharge is dependent not only on conservation capital stock, but also on variable rainfall. With constant extraction cost, average recharge is a perfect substitute for stochastic recharge. In reality, extraction costs will vary with temporary shortfalls in recharge, but only slightly, inasmuch as extraction cost is a function of lift (well elevation - minimum head) which is somewhat insensitive to feasible variation in short-run head.
} 
modeled as a single stock, in reality, there are a variety of available recharge-augmenting instruments such as fencing for feral ungulates, which prevents the destruction of upland vegetation; reforestation of native flora, which can decrease evapotranspiration and surface runoff; and manmade engineering structures designed to increase infiltration and/or decrease runoff. Optimal watershed management therefore involves selecting a portfolio of instruments that maximizes recharge benefits net of investment costs. ${ }^{8}$ Inasmuch as we are interested primarily in the impact of investment $(I)$ on aquifer-level groundwater extraction trajectories, we assume that all expenditures are allocated optimally amongst available conservation instruments. Investment enters the resource manager's problem as a control variable. Capital stock depreciates at an exogenous rate $(\delta)$, but the resource manager can steer the time path of capital stock, and hence recharge, by choosing the expenditure on investment in every period. The integrated watershedaquifer system is depicted in figure 1.

\footnotetext{
${ }^{8}$ In this analysis, we focus on the groundwater recharge benefits of watershed conservation. In general, benefits would include other ecosystem services such as reduced flooding, reduced sedimentation, biodiversity, and recreation.
} 


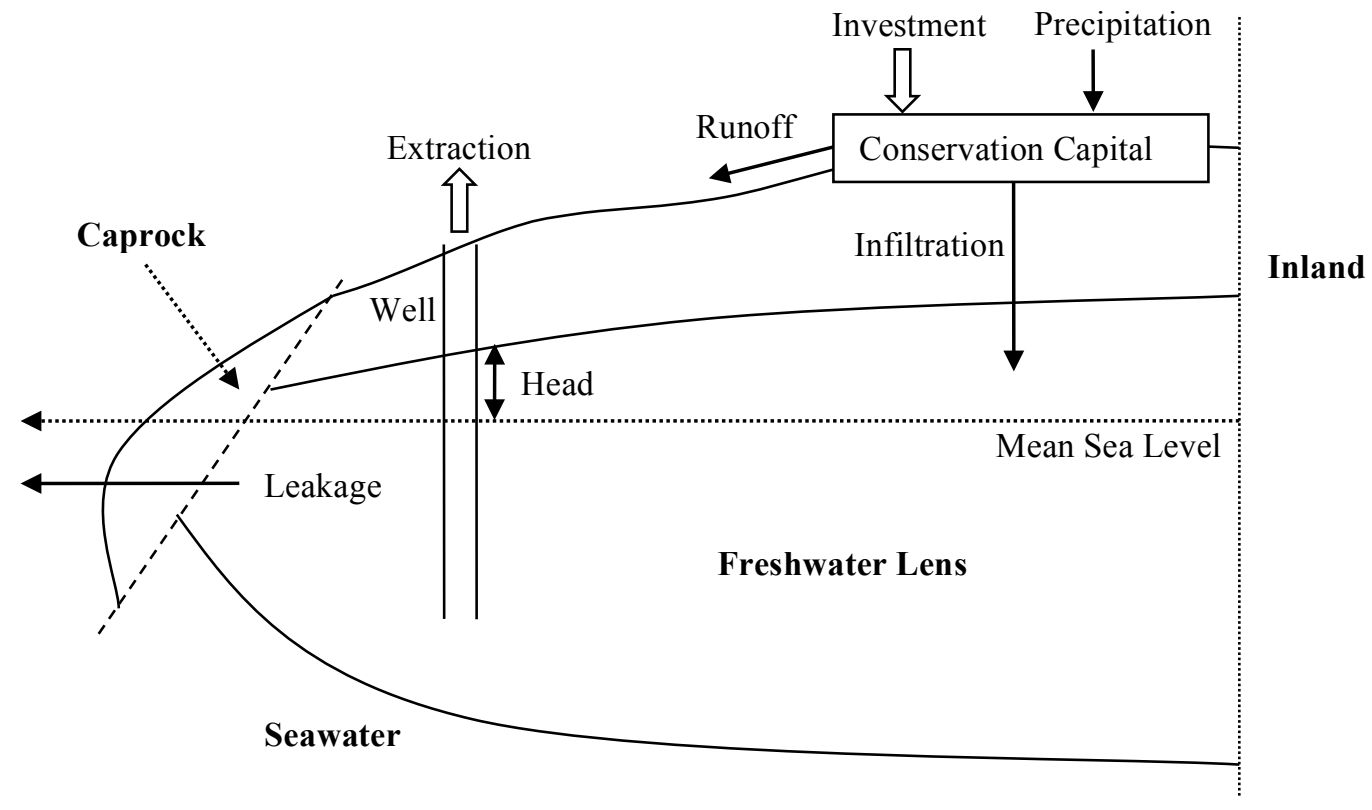

Figure 1. Coastal watershed-aquifer system

\subsection{The resource manager's maximization problem}

When demand for water is growing over time, traditional water resources eventually need to be supplemented by a backstop such as desalinated seawater. The resource manager must choose the rates of groundwater extraction $(q)$, desalination $(b)$ and investment $(I)$ in every period, ${ }^{9}$ given a discount rate $r>0$ to maximize the net present value of social welfare: ${ }^{10}$

$$
\underset{q_{t}, b_{t}, I_{t}}{\operatorname{Max}} \int_{0}^{\infty} e^{-r t}\left\{\int_{0}^{q_{t}+b_{t}} D^{-1}\left(x_{t}\right) d x_{t}-\left[c_{q}\left(X_{t}\right)+c_{d}\right] q_{t}-\left[c_{b}+c_{d}\right] b_{t}-c_{I} I_{t}\right\} d t
$$

subject to $\quad \dot{X}_{t}=R\left(N_{t}\right)-L\left(X_{t}\right)-q_{t}$

\footnotetext{
${ }^{9}$ Because of the long-run nature of the management problem, we abstract from time lags, and each period represents a single year. If short-run issues are of interest, the model should be modified to include time lags for the aquifer's state equation.

${ }^{10}$ Consistent with the theory of sustainable income (Weitzman, 1997) and measures of sustainability (Dasgupta, 2001; Dasgupta, 2009; Stiglitz et al., 2010), prices hereafter correspond to first-best shadow prices derived from the dynamic optimization problem (1).
} 


$$
\begin{aligned}
& \dot{N}_{t}=I_{t}-\delta N_{t} \\
& I_{t} \in\left[0, I_{\text {max }}\right],
\end{aligned}
$$

standard non-negativity constraints on the control variables, and initial conditions $\left(N_{0}, X_{0}\right)$. Gross benefits from water consumption are measured as the area under the inverse demand curve $\left(D^{-1}\right)$. Total costs are calculated using the unit extraction cost of groundwater $\left(c_{q}\right)$, the unit cost of desalinating seawater $\left(c_{b}\right),{ }^{11}$ the unit distribution cost $\left(c_{d}\right)$ and the unit cost of investment $\left(c_{I}\right)$. Investment is bounded below by zero and above by $I_{\max }$, which denotes some maximum feasible investment rate, determined for example, by budgetary restrictions.

Using optimal control, we characterize the necessary conditions for the optimum management of the two resources. The Current Value Hamiltonian corresponding to the maximization problem (1) is:

$$
\begin{aligned}
H= & \int_{0}^{q_{t}+b_{t}} D^{-1}\left(x_{t}\right) d x_{t}-\left[c_{q}\left(X_{t}\right)+c_{d}\right] q_{t}-\left[c_{b}+c_{d}\right] b_{t}-c_{I} I_{t} \\
& +\lambda_{t}\left[R\left(N_{t}\right)-L\left(X_{t}\right)-q_{t}\right]+\mu_{t}\left[I_{t}-\delta N_{t}\right]
\end{aligned}
$$

The Maximum Principle requires that the following conditions hold:

$$
\begin{array}{ll}
\frac{\partial H}{\partial q_{t}}=D^{-1}\left(q_{t}+b_{t}\right)-c_{q}\left(X_{t}\right)-c_{d}-\lambda_{t} \leq 0, & \text { if }<\text { then } q_{t}=0 \\
\frac{\partial H}{\partial b_{t}}=D^{-1}\left(q_{t}+b_{t}\right)-c_{b}-c_{d} \leq 0, & \text { if }<\text { then } b_{t}=0 \\
\dot{\lambda}_{t}-r \lambda_{t}=-\frac{\partial H}{\partial X_{t}}=c_{q}^{\prime}\left(X_{t}\right) q_{t}+\lambda_{t} L^{\prime}\left(X_{t}\right) &
\end{array}
$$

\footnotetext{
${ }^{11}$ Typically, desalination requires a large and irreversible sunk cost. Inasmuch as our focus is on how to jointly price water and recharge services generated by watershed conservation, however, we assume that $c_{b}$ includes amortized capital costs.
} 


$$
\begin{aligned}
& \dot{X}_{t}=\frac{\partial H}{\partial \lambda_{t}}=R\left(N_{t}\right)-L\left(X_{t}\right)-q_{t} \\
& \dot{\mu}_{t}-r \mu_{t}=-\frac{\partial H}{\partial N_{t}}=-\lambda_{t} R^{\prime}\left(N_{t}\right)+\mu_{t} \delta \\
& \dot{N}_{t}=\frac{\partial H}{\partial \mu_{t}}=I_{t}-\delta N_{t}
\end{aligned}
$$

Along the optimal trajectory, groundwater must be extracted until its marginal benefit is equal to its marginal cost in every period. The efficiency price of water, therefore, is determined where the equimarginality condition is satisfied, and we define it as $p_{t} \equiv D^{-1}\left(q_{t}+b_{t}\right)$. More specifically, the necessary condition (3) for optimal groundwater extraction requires that royalty (price minus unit extraction cost) is equal to the shadow price or marginal user cost of water $\left(\lambda_{t}\right)$ plus distribution cost. Equivalently, the efficiency price is equal to the marginal opportunity cost (MOC) of groundwater, or the sum of marginal extraction, distribution and marginal user costs. The condition is none other than a modified version of the Hotelling rule for the optimal extraction of a natural resource. ${ }^{12}$

The adjoint equation or the equation of motion for the first costate variable (5) can be rearranged as follows:

$$
\dot{\lambda}_{t}-c_{q}^{\prime}\left(X_{t}\right) q_{t}=r \lambda_{t}+\lambda_{t} L^{\prime}\left(X_{t}\right)
$$

Equation (9) says that the marginal benefit of conserving water should be equated to the cost of the marginally-conserved unit of groundwater. The marginal benefit includes the increase in royalty and the decrease in extraction cost, while the marginal cost includes the forgone interest from the royalty and the lost value resulting from increased leakage.

\footnotetext{
${ }^{12}$ The basic Hotelling rule is extended to include stock-dependent extraction costs and resource growth.
} 
The costate variable is by definition the increase in net present value resulting from an additional unit of the groundwater stock. From a cost perspective, it is the loss in value when the stock is reduced by one unit, i.e. the marginal user cost. We manipulate the necessary conditions to eliminate $\lambda_{t}$, thus allowing us to write the efficiency price as the sum of unit extraction, distribution, and marginal user cost. For $q_{t}>0$, it is straightforward to derive the following efficiency price equation: ${ }^{13}$

$$
p_{t}=c_{q}\left(X_{t}\right)+c_{d}+\underbrace{\frac{\dot{p}_{t}-c_{q}^{\prime}\left(X_{t}\right)\left[R\left(N_{t}\right)-L\left(X_{t}\right)\right]}{r+L^{\prime}\left(X_{t}\right)}}_{\text {marginal user cost }}
$$

The marginal user cost takes into account the forgone use of the marginal unit when price is higher in the future, the value of the resulting decrease in leakage, and the increase in marginal extraction cost. Equation (10) remains unchanged when watershed conservation is not part of the resource management strategy, i.e. when $I_{t}=0 \forall t$. The actual price paths will differ, however, inasmuch as the trajectory of aquifer recharge is influenced by the capital stock.

The capital stock has an equimarginality condition similar to that for the stock of groundwater. For $\mu_{t}=c_{I}$, i.e. at the singular solution $N^{*},{ }^{14}$

$$
c_{I}(r+\delta)=\lambda_{t} R^{\prime}\left(N_{t}\right)
$$

The marginal cost can be thought of as the implicit rental price or user cost of capital (Jorgensen, 1963), which includes the forgone interest that would have accrued had the

\footnotetext{
${ }^{13}$ To derive equation (10), take the time derivative of equation (3), substitute the result with equations (3) and (6) into equation (9), and rearrange.

${ }^{14}$ Singular solutions arise in problems where the Hamiltonian is linear in a control variable. When the switching function becomes zero over some time interval, the maximum principle does not specify the optimal value of the control variable. Instead, the singular solution must be used to characterize the optimal value of the control variable (e.g. Conrad and Clark, 1987).
} 
income not been spent on conservation capital, and the cost of depreciation. The marginal benefit or shadow price of investment is the marginal contribution of capital to recharge, valued at the shadow price of groundwater. Dividing both sides of (11) by $R^{\prime}\left(N_{t}\right)$ converts the left side of the equation to \$/volume and reveals that at the optimum, the planner should be indifferent between conserving water via investment and via consumption reduction:

$$
\frac{c_{I}(r+\delta)}{R^{\prime}\left(N_{t}\right)}=\lambda_{t} .
$$

The left hand side of (12) can be viewed as a supply curve for recharge. Inasmuch as the marginal productivity of conservation capital is diminishing, the marginal cost of providing a unit of recharge is upward sloping. Welfare is maximized where the recharge supply curve intersects the shadow price of groundwater, which is equivalent to the net marginal benefit from a unit of recharge as determined endogenously by condition (3).

Since the current value Hamiltonian (2) is linear in $I_{t}$, investment is expected to follow a most rapid approach path (MRAP) to the steady state. One can define a switching function using the coefficient of $I_{t}$ :

$$
\sigma_{t} \equiv \mu_{t}-c_{I}
$$

Then along the optimal trajectory for investment, it must be that

$$
I_{t}= \begin{cases}I_{\max } & \text { if } \sigma_{t}>0 \\ 0 & \text { if } \sigma_{t}<0\end{cases}
$$

The optimal investment rule is to choose the maximum feasible level of investment when the costate variable $\mu_{t}$ exceeds the marginal cost of investment, and choose zero investment if the cost is instead higher than the value of $\mu_{t}$. 


\subsection{Characterization of the steady state}

To operationalize the investment rule, we rewrite equation (14) in terms of the singular solution for the capital stock $\left(N^{*}\right)$. Following Conrad and Clark (1987), we start by setting the coefficient of the relevant control in the Hamiltonian equal to zero, which amounts to setting equation (13) equal to zero. The result is then substituted into the adjoint equation for $\mu_{t}$, which yields equation (11). In the steady state, $\dot{p}_{t}=\dot{X}_{t}=\dot{N}_{t}=0$ and $p^{*}=c_{b}$. Then the solution $N^{*}$, which belongs to a vector $\left(p^{*}, X^{*}, N^{*}\right)$ that simultaneously satisfies equations (10) and (11), is the singular solution for the capital stock. $^{15}$

The complete solution for investment is given by:

$$
I_{t}= \begin{cases}I_{\max } & \text { if } N_{t}<N^{*} \\ I^{*}=\delta N^{*} & \text { if } N_{t}=N^{*} \\ 0 & \text { if } N_{t}>N^{*}\end{cases}
$$

If the level of capital stock is below its steady state level, the resource manager should invest at the maximum feasible rate in every period until $N^{*}$ is reached. If instead the capital stock starts off at a relatively high level, then one should optimally allow the capital stock to depreciate until the steady state level is obtained, at which point $I^{*}=\delta N^{*}$

Upon solving for the values of $X^{*}$ and $N^{*}$, one can also obtain the steady state values of groundwater extraction and desalination. Since $\dot{X}_{t}=0$ in the steady state, the equation of motion for the aquifer stock (6) implies that $q^{*}=R\left(N^{*}\right)-L\left(X^{*}\right)$. In other words, extraction should be constant and equal to recharge net of natural leakage. Any

\footnotetext{
${ }^{15}$ Assuming the existence of a unique steady state, the singular solution coincides with the steady state capital stock.
} 
quantity demanded in excess of net recharge is therefore supplied by desalination, i.e. $b^{*}=D\left(c_{b}+c_{d}\right)-q^{*}$.

\subsection{Transition to the steady state}

The price equation (10), the capital accumulation equation (8), and the governing equation for groundwater stock (6) comprise a differential system that can be solved given proper boundary conditions. Field measurements of the initial groundwater level and information about status quo conservation measures are likely available in practice. The steady state price is determined by the cost of the backstop when demand is growing over time, and the terminal values for both state variables can be determined as outlined in section 3.3.

Inasmuch as the Hamiltonian is linear in investment, the dynamic paths of capital stock and investment will approach monotonically from above or below the steady state target, depending on the initial value $N_{0}$. The Hamiltonian is not linear in groundwater extraction, however. Consequently, the optimal trajectories of the groundwater stock, efficiency price, and extraction will not follow a simple MRAP to the steady state. In fact, non-monotonic stock trajectories may turn out to be optimal under certain circumstances, inasmuch as the result has been established for the case of constant aquifer recharge (e.g., Krulce et al., 1997).

In some situations, use of a backstop resource such as desalination may never be cost effective, e.g. when population and per capita income is stable. This is a special case of the general model wherein the steady state stock is greater than its minimum allowable level. While the first-order conditions governing transition to the steady-state remain the 
same, the actual extraction path converges to a stock whose efficiency price is lower than the backstop resource (Koundouri and Christou, 2006).

\subsection{The decentralized solution: private water charges and PES}

The previous section derived the optimality conditions for simultaneous management of upstream watershed conservation and downstream groundwater extraction from the point of view of a hypothetical social planner. In this section, we show that the same outcome can be achieved in a decentralized framework if the appropriate water prices and ecosystem payments are implemented simultaneously. Optimal PES pricing extends the market solution to the non-market ecosystem service (groundwater recharge) such that payments make the upstream landowners better off. However, presenting downstream users with marginal prices, while increasing recharge provision, makes them better off as well.

If there were numerous owners of groundwater aquifers, each of whom were supplied by a single owner of recharge services, and said ownership were competitively traded, private contracts between groundwater and recharge-service owners would evolve to automatically satisfy the optimality conditions in the spirit of Debreu-Scarf (DebreuScarf, 1963; Nechyba, 2010). We abstract from governance issues ${ }^{16}$ such that a single authority (public utility) can exercise control even if there are many extractors. The public utility will be viewed as a regulated monopolist, who is not allowed to keep revenue surplus (above physical extraction and distribution costs) generated from sales to

\footnotetext{
${ }^{16}$ In reality, the first-best solution may be unattainable when enforcement and information costs are considered. Which of several institutions (e.g. privatization, centralized ownership, user associations) maximizes the net PV of the resource depends on the relative benefits of each candidate institution net of governance costs.
} 
consumers. The efficiency price of groundwater (equation 10) exceeds the physical costs of extraction and distribution by exactly the MUC along the optimal trajectory. Thus, the optimal rate of groundwater extraction can be achieved by pricing according to (10) and returning the surplus to consumers as a lump sum payment. ${ }^{17}$ Since pricing at physical cost also yields zero surplus, the utility should be indifferent between the two prices, which means that the decentralized solution can be made to emulate the social optimum.

Optimal ecosystem payments must also be implemented simultaneously to ensure that social welfare is maximized. Consider the case where ecosystem services are chosen by private landowners, who provide a public input (recharge) to the single groundwater aquifer. ${ }^{18}$ Private producers of the ecosystem service will invest in watershed conservation as long as the payments received from doing so exceed the costs, and the decision is made independent of water extraction. In other words, the producers care only about the payments they receive, not about the recharge benefits generated by their actions. In a given period $t$, the problem is to

$$
\operatorname{Max}_{I_{t}}\left[\left(\pi_{t}-c_{I}\right) I_{t}+v\right]
$$

where $\pi_{t}$ is the ecosystem payment received for one unit of conservation investment and $v$ is the PV of benefits for conservation land ownership (e.g. status value). ${ }^{19}$ For $\pi_{t}>c_{I}$,

\footnotetext{
${ }^{17}$ In practice, this can be achieved by block pricing, where an inframarginal block is given for free or at least charged less than the full marginal cost (see also section 4.1).

${ }^{18}$ We take up the problem of public ownership of the watershed in section 4.2.

${ }^{19}$ To simplify the problem, we suppose that the land is already designated for conservation purposes and that owners hold the land for speculative or status-enhancing purposes, as is the case in Hawai' $i$. Generally, a landowner could be obtaining rents for the land's best alternative use. To account for the opportunity cost of conservation, the model would need to be modified to include a participation constraint, i.e. accepting payments must make the provider of services at least as well off as not providing said services. This can be implemented by establishing a baseline such that paying for services above the baseline would not make the provider worse off - the marginal price multiplied by the difference between actual provision and baseline provision would offset the opportunity cost of conservation, i.e. it would leave the provider's welfare unchanged.
} 
the landowner would theoretically invest an infinite amount. If instead $\pi_{t}<c_{I}$,

investment will be zero. For $\pi_{t}=c_{I}$, the solution corresponds to the optimal singular path in the social planner's problem, as long as

$$
\pi_{t}=\frac{\lambda_{t} R^{\prime}\left(N_{t}\right)}{r+\delta}
$$

Thus, the decentralized solution for ecosystem service provision emulates the social optimum if the government sets the payment for each unit of investment equal to the shadow price of investment, i.e. the future change in recharge associated with a unit of investment, valued at the shadow price of groundwater and discounted to the present. ${ }^{20}$ The socially optimal level of investment can equivalently be achieved by setting the ecosystem payment for recharge provision (rather than investment) equal to $\lambda_{t} /(r+\delta)$. Intuitively, the payment for a unit of recharge should be the shadow price of groundwater, adjusted for the discount rate and depreciation of the capital stock.

\subsection{Model sensitivity}

In section 3, we solved for equimarginality conditions that, if satisfied, correspond to optimal resource extraction and conservation investment. The actual trajectories of the various control and state variables, i.e. the outcome of the model, will depend on the values of different parameters such as the backstop cost and those that influence the shape of the extraction cost and leakage functions. While a detailed numerical sensitivity analysis would help to characterize the spectrum of reasonable possible outcomes, such an application is beyond the scope of this paper. In lieu of a numerical application, we

\footnotetext{
${ }^{20}$ Technically, the ecosystem service is recharge, so the payments should be conditional on the actual delivery of the service. Uncertainty aside, the investment is valued based on the generated recharge, which essentially amounts to the same thing.
} 
discuss how the model responds to changes in the value of the backstop $\operatorname{cost} c_{b}$. Similar logic could be applied to other parameters of interest.

A higher value of $c_{b}$, ceteris paribus, implies a higher optimal steady state price as well as a higher marginal opportunity cost of water in transition to the steady state. If the MOC of water is higher, the shadow price of water is necessarily higher, which corresponds to a larger marginal benefit of watershed investment. Since at the optimum the $\mathrm{MB}$ of investment is equal to the discounted sum of the values of marginal increases in recharge and also equal to the $\mathrm{MC}$ of investment $\left(c_{I}\right)$, a higher $\mathrm{MB}$ calls forth more supply of investment but not enough to entirely offset the original increase in water price. To prove this assume the opposite - that the increase in investment depresses the efficiency price by more than the original increase (i.e. $\mathrm{p}_{2}<\mathrm{p}_{1}$ ). But this would imply that the shadow price of investment is lower after the change. To achieve the lower shadow price, equation (17) requires that $N_{2}>N_{1}$ given that $\lambda_{2}<\lambda_{1}$ by the assumption that the efficiency price for water is lower than the original level. But that cannot be optimal, since the MB of investment in both cases should be equal to $c_{l}$, the MC of investment.

\section{Financing watershed conservation}

In section 3.5 we provided a simultaneous derivation of the prices to be charged to groundwater consumers and the price to be paid to ecosystem-service providers. This leaves the question of how to finance PES and how that relates to the revenues generated from water pricing. One way to finance a comprehensive watershed conservation 
program is through benefit taxation. ${ }^{21}$ Groundwater consumers ultimately benefit from the enhanced recharge that watershed conservation provides through lower water prices and delayed implementation of costly desalination. At first blush, a volumetric tax on groundwater consumption may seem ideal; it targets the beneficiaries, lowers consumption, and provides revenue to finance investment in recharge capacity. However, while optimal investment moderates water scarcity and shifts the MOC for groundwater downward, a volumetric tax $(\tau)$ has the opposite effect on consumption (figure 2). Charging consumers a higher price takes away part of the benefits of investment, exactly what the resource manager is trying to avoid. Moreover, from a welfare standpoint, volumetric charges put a disproportionately large burden of investment costs on current generations, even though future generations are likely to benefit most from the program. A lump-sum tax can preserve efficient incentives as well as distribute project costs in accordance with benefits.

\footnotetext{
${ }^{21}$ Using a probabilistic recharge-loss scenario and a particular watershed conservation plan, Pitafi and Roumasset (2003) propose dynamic benefit taxation as a means of financing conservation investment, while preserving intergenerational equity.
} 


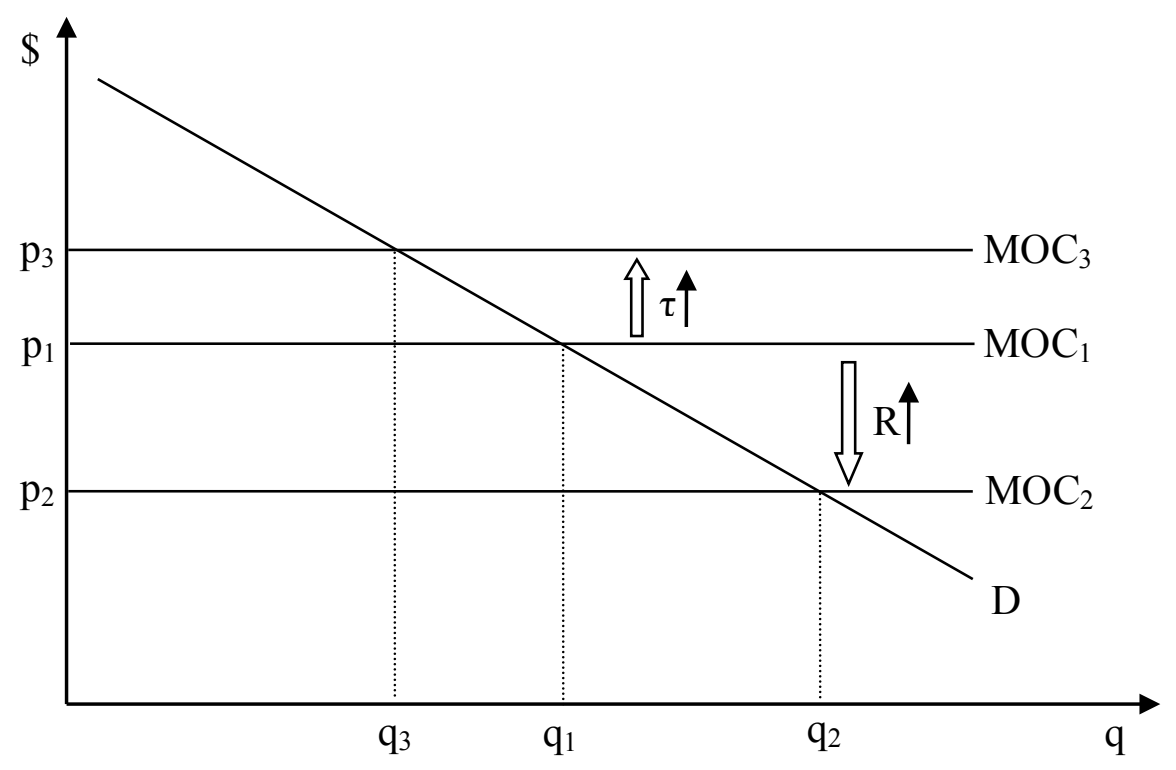

Figure 2. Investment in watershed conservation shifts the $\mathrm{MOC}$ of groundwater downward (e.g. from $\mathrm{MOC}_{1}$ to $\mathrm{MOC}_{2}$ ) and increases optimal water consumption (e.g. from $\mathrm{q}_{1}$ to $\mathrm{q}_{2}$ ). On the other hand, a volumetric tax on water consumption increases the price faced by consumers, i.e. shifts the $\mathrm{MOC}$ of groundwater upward (e.g. from $\mathrm{MOC}_{1}$ to $\mathrm{MOC}_{3}$ ) and decreases optimal water consumption (e.g. from $\mathrm{q}_{1}$ to $\mathrm{q}_{3}$ ).

Results from the previous section indicate that the optimal integrated management of a watershed and a downstream groundwater resource can be achieved by both centralized and decentralized means. Given that the MOC of groundwater exceeds the physical costs of extraction and distribution by marginal user cost, efficiency pricing of water generates a surplus. At the same time, the diminishing marginal product of conservation capital in recharge generates an upward sloping marginal cost curve for recharge provision (12), which implies that efficient pricing of ecosystem services also generates a surplus. Thus in the private case, the combined surplus is sufficient to finance the requisite investment. When the size of a conservation project is determined exogenously or the conservation instrument exhibits non-convexities, however, the finance mechanism is not so straightforward. Large public projects may, for example, 
incur substantial costs in initial periods, even though most of the benefits are generated in future periods. In section 4.2, we derive a lump-sum benefit tax that finances a public conservation project, maintains a balanced intergenerational budget, and preserves efficient incentives for groundwater consumers.

\subsection{Financing PES in the decentralized case}

As discussed in section 3, the shadow price of the ecosystem service derived from the optimization model should be equal to the payment that would induce the desired level of conservation. Optimal ecosystem pricing generates a surplus $(s)$ for the service provider equal to

$$
s_{t}=\lambda_{t}-\frac{c_{I}(r+\delta)}{R^{\prime}\left(N_{t}\right)}
$$

for each unit of recharge provided. The surplus tends to be larger when conservation investment is relatively inexpensive and the endogenous value of the ecosystem service is high. At the same time, pricing groundwater at marginal opportunity cost generates perunit revenue surplus equal to the marginal user cost, which can be returned in lump sum fashion to water consumers via appropriate block pricing (e.g. Pitafi and Roumasset, 2009). To ensure optimal groundwater consumption, the price need only be correct at the margin, i.e. the relevant price tier should be set equal to the marginal opportunity cost of water. For the case of two price blocks, the size of the first block can be set such that any revenue surplus remaining after covering conservation investment $\operatorname{costs}\left(I^{*} c_{I}\right)$ is returned to water users through free inframarginal units of water. ${ }^{22}$ Figure 3 depicts a hypothetical

\footnotetext{
${ }^{22} \mathrm{We}$ discuss the solution as if there is a single aggregate downstream consumer. When considering multiple heterogeneous users, one could allocate the surplus based on equity criteria by differentiating
} 
block pricing structure, where $z^{*}$ represents the total surplus from efficiency groundwater and ecosystem pricing, and landowners are left no better or worse off, i.e. the payments exactly offset the investment costs. ${ }^{23}$

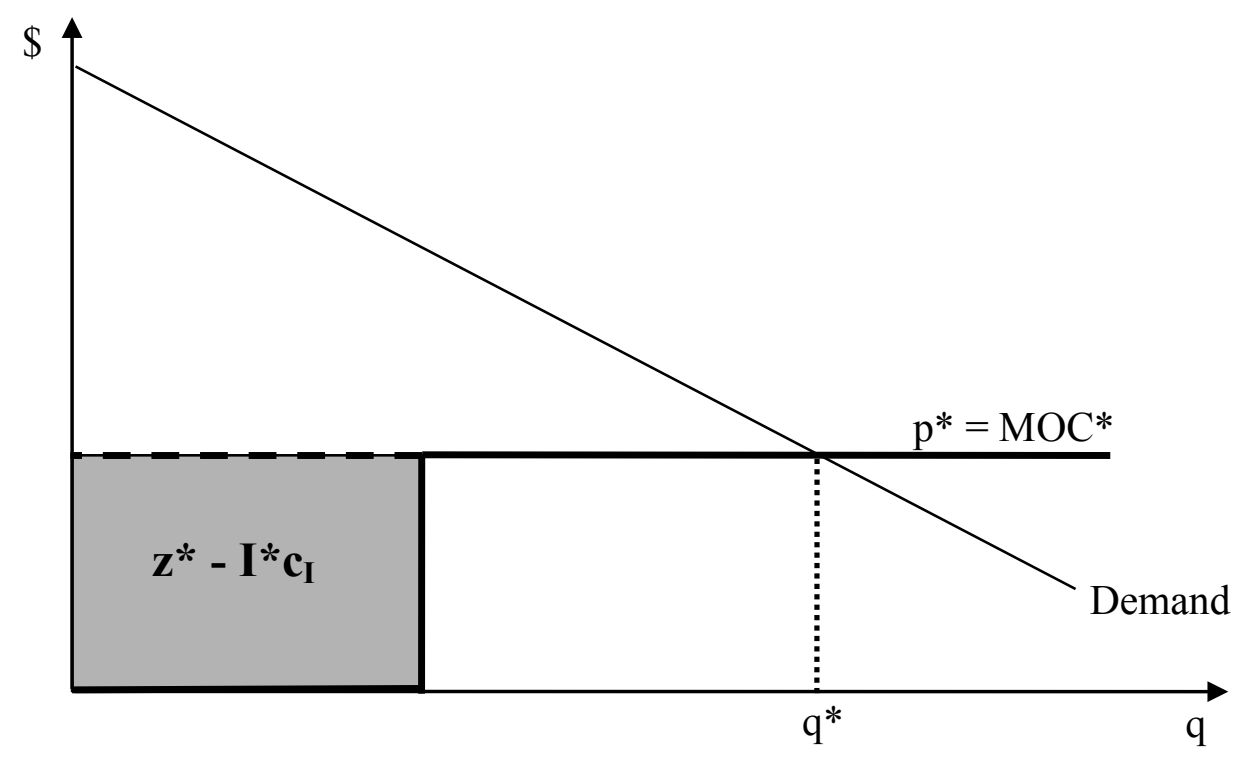

Figure 3. An increasing block pricing structure finances conservation and returns revenue surplus to water consumers.

\subsection{Financing public project-based conservation}

In some instances, the size of a conservation project is determined exogenously by policymakers or the conservation instrument may exhibit non-convexities that render marginal product pricing infeasible. In Hawai' $i$, for example, feral ungulates cause substantial destruction to many upland watershed areas. One means of conservation is to fence in a large area and remove the animals. If the fencing is expanded to cover the most

prices. That is beyond the scope of this section, however. Our primary objective is to compare finance mechanisms under different assumptions about watershed conservation instruments.

${ }^{23}$ If the land has alternative uses, as is generally the case, some of the surplus being returned to groundwater users would have to be reallocated to landowners to account for their opportunity costs. 
crucial upland areas, it is likely to traverse multiple land plots, meaning it should be implemented and financed as a public project. Thus, while the efficiency price of water is still governed by equation (10), the capital stock is given exogenously and is dominated by initial investment. If the revenue surplus from groundwater is not sufficient to cover initial investment, bond-financing will be required, such that the present value of collections is equal to the present value of investment.

A lump sum benefit tax can preserve efficient incentives, while maintaining a balanced intergenerational budget. One approach to benefit taxation is to set the costs of conservation investment proportional to the benefits. The idea of proportional benefit taxation is sometimes attributed to Wicksell (1958), ${ }^{24}$ although technically the only requirement of Wicksell's political model is unanimity. ${ }^{25}$ Inasmuch as Wicksellian taxes can be anything less than benefits, proportional benefit taxation is one appealing candidate. ${ }^{26}$ Other possibilities include concepts from cooperative game theory such as the Shapley value (Shapley, 1953), as well as concepts from the theory of public goods such as Lindahl pricing (e.g., Lindahl, 1958; Hines, 2000), according to which public good provision is supported by individual-specific prices set equal to marginal valuations. Although we assume a representative consumer in every period, water users are differentiated across time by the benefits they receive. The net benefit from water use

\footnotetext{
${ }^{24}$ See e.g., Backhaus and Wagner (2004) and Shughart and Razzolini (2003).

${ }^{25}$ The lump-sum tax ensures Pareto-improvement across generations, i.e., each generation $t$ as a whole is made better off with the program, but not within generations. An instrument that leaves every single individual (within and across generations) better off would require a higher level of sophistication as well as more individualized information. See Pitafi and Roumasset (2009) for an application of (Paretoimproving) proportional benefit taxation to finance pricing reform in a spatial and intertemporal context of groundwater management.

${ }^{26}$ As shown in Libecap (1989) and Dixit (2004), cooperation is enhanced by simplicity. Where water consumers are heterogeneous in terms of benefits, proportional taxation is a relatively simple scheme that satisfies the Wicksellian criterion. In general, the cooperation induced by unanimity need not lead exactly to proportional benefit taxation.
} 
obtained by a representative generation- $t$ consumer when the aquifer and watershed are jointly optimized is calculated as:

$$
\hat{V}_{t}=\int_{0}^{\hat{q}_{t}+\hat{b}_{t}} D^{-1}\left(x_{t}\right) d x_{t}-\left[c_{q}\left(\hat{X}_{t}\right)+c_{d}\right] \hat{q}_{t}-\left[c_{b}+c_{d}\right] \hat{b}_{t}
$$

In the discussion that follows, the symbol ${ }^{\wedge}$ is used to denote the paths or values of variables under optimal integrated management, while ${ }^{\sim}$ represents those paths or values derived from (suboptimal) status quo management. The generation- $t$ benefit obtained by optimizing groundwater extraction, taking the status quo conservation as given can be calculated as: $:^{27}$

$$
\tilde{V}_{t}=\int_{0}^{\tilde{q}_{t}+\tilde{b}_{t}} D^{-1}\left(x_{t}\right) d x_{t}-\left[c_{q}\left(\tilde{X}_{t}\right)+c_{d}\right] \tilde{q}_{t}-\left[c_{b}+c_{d}\right] \tilde{b}_{t}
$$

The period- $t$ welfare gain from the conservation program is therefore $\hat{V}_{t}-\tilde{V}_{t}$.

We denote the exogenously determined PV cost of the public project as $\hat{C}$. Since the present value of collections must be sufficient to cover the investment costs, and the per-period tax is calculated as a proportion $(\alpha)$ of the periodic welfare gain, the following condition must be satisfied:

$$
\hat{C}=\int_{0}^{\infty} e^{-r t}\left[\alpha\left(\hat{V}_{t}-\tilde{V}_{t}\right)\right] d t \Rightarrow \hat{\alpha}=\hat{C} / \int_{0}^{\infty} e^{-r t}\left[\hat{V}_{t}-\tilde{V}_{t}\right] d t
$$

The efficient lump-sum tax for the representative generation- $t$ consumer is

$$
\hat{\tau}_{t}=\hat{\alpha}\left(\hat{V}_{t}-\tilde{V}_{t}\right)
$$

\footnotetext{
${ }^{27}$ The benchmark could be measured in a variety of different ways. For example, one could also consider the trajectory of capital stock for zero investment or require just maintenance for a chosen benchmark year. The methodology is applicable to whichever benchmark is most appropriate for the particular application.
} 
If one has reason to believe that the political process would yield a tax system that is not proportional, e.g. one in which certain generations bear a larger proportion of the costs, then the tax formula (22) can be adjusted by replacing $\hat{\alpha}$ with $\alpha_{t}$, where $\alpha_{t}$ varies between generations and is determined exogenously. Proportional benefit taxation is used in this analysis, however, because it theoretically limits rent-seeking behavior. A group of beneficiaries cannot alter its relative tax share; an increase or decrease for one group means an increase or decrease for all. With a progressive tax structure, the degree of progression is open to rent-seeking.

\subsection{Discussion}

Proportional benefit taxation makes sense as long as $\hat{V}_{t}>\tilde{V}_{t}$ for all $t$, i.e. consumers in every period gain from the watershed conservation plan. If there are negative beneficiaries, proportional payments (even if negative) would leave some consumers worse off, since they would only be compensated for a proportion of their reduction in benefits. A Pareto-improving outcome can still be achieved, however, by increasing the proportional collection of benefit taxes from the winners (those consumers for whom $\hat{V}_{t}>\tilde{V}_{t}$ ) in order to leave the losers (those consumers for whom $\hat{V}_{t}<\tilde{V}_{t}$ ) just as well off as they were without the watershed management plan. The tax collection would be higher per household in this scenario, inasmuch as the winners must compensate the losers in addition to financing investment in conservation.

Whether the conservation surcharges can be truly classified as "lump-sum" depends on consumers' elasticity with respect to the fixed fee. The analysis thus far has maintained the assumption of perfect inelasticity, but the literature on public utilities 
suggests that this is not always the case. For example, Rodini et al. (2003) find that mobile phone services exhibit some substitutability with telephone landlines, particularly with a second fixed line. An increase in the monthly fixed charge for a landline might induce a switch to mobile phone service. Such a fee increase, while not volumetric, is also not lump-sum, since it affects the user's landline consumption decision. Although there are few analogous alternatives for potable water, a conservation surcharge may affect household formation, thus making consumers less than perfectly inelastic.

Implementing the watershed conservation tax would require enabling legislation to allow water utilities to change their principles of finance in localities where the utility is allowed to finance construction and maintenance of groundwater infrastructure but not for maintaining nature's infrastructure for aquifer recharge. Inasmuch as investment costs are concentrated in the initial periods and benefits concentrated in future periods, financing a watershed conservation program requires borrowing. One way to borrow the requisite funds is for the government to issue a bond. The water-managing agency would collect watershed surcharges from water users on the government's behalf, and another agency might ultimately carry out the conservation project, which would be funded by part of the surcharges, and the remainder would be used to pay off the bond.

The problem becomes slightly more complicated, when heterogeneous users are considered. The analysis thus far has proceeded on the assumption that each generation can be sufficiently characterized by a representative consumer. The benefit principle should still extend to various types of users, provided that welfare gains can be differentiated by user, i.e. there is sufficient information regarding the preferences or demand functions of every household. 


\section{Watershed conservation as climate adaptation}

Available research indicates that climate change will affect groundwater recharge rates and levels in a multitude of ways, although the regional magnitude, and in some cases the direction, of such impacts remain uncertain (IPCC, 2007b). Climate change may lead to changes in vegetation, and hence evapotranspiration (ET), which affects recharge to groundwater aquifers. An increase in temperature would also affect ET and consequently recharge, inasmuch as more water would evaporate before having the opportunity to infiltrate back into the ground. In addition, sea level rise may lead to saltwater intrusion of coastal aquifers, reducing the usable portion those resources. Climate change models predict an increase in the frequency of heavy rainfall events in many areas (IPCC, 2007a), which in turn increases the risks of floods, adversely affects the quality of groundwater resources, and may negatively affect recharge depending on how much of the concentrated rainfall is lost as runoff. In many regions, aquifer recharge is likely to decrease (IPCC, 2007a) unless the quality of watersheds is improved. The discussion that follows focuses on such areas in which the decline in recharge dominates a possibly higher level of average annual rainfall.

In addition to climate change, there are other reasons why a watershed may not be in a steady state condition. In some locales, logging is a source of livelihood for residents and the forest stock acts as a natural asset which can be quickly liquidated should the need arise. Events such as landslides, which cause catastrophic damage to delicate watershed ecosystems, naturally occur and climate change will likely increase the frequency of such occurrences. Watersheds are also constantly being threatened by new and existing invasive species. Invasive species alter existing land cover in otherwise 
balanced ecosystems, which results in increased runoff, decreased evapotranspiration, or both. Consequently, without watershed conservation, recharge decreases over time.

If recharge is declining over time, the excess burden of not properly managing the watershed is higher. When water is scarcer, i.e. when the MUC of groundwater $\left(\lambda_{t}\right)$ is higher, the optimality condition (11) indicates that the benefit of the marginal unit of conservation capital is higher, all else equal. In addition, if climate change negatively affects the existing conservation capital stock directly (e.g. the native forest stock), the marginal benefit of investment is even larger, given the concave shape of the recharge function. Consequently, it is optimal to maintain a higher capital stock with climate change, even though the resulting recharge rate is lower. Additional costly investment is required, but the value of the recharge services provided by the watershed is also higher.

\section{Conclusion}

Payments for ecosystem services should account for management decisions of interdependent resources. In this paper, we develop a methodology for valuing an upstream ecosystem service (groundwater recharge by a watershed) given optimal joint management of groundwater and watershed conservation. Conservation investment reduces the shadow price of groundwater relative to optimizing the groundwater alone, and the gain in the present value of consumer surplus created by the groundwater price differential serves as a lower bound to the benefits of forest conservation without explicit measurement of benefits such as recreation, biodiversity, and cultural values.

Ignoring conservation costs is analogous to pricing water without considering groundwater infrastructure expenses. Both physical and natural capital are part of the 
optimal solution. However, simply adding volumetric conservation surcharges to the previous efficiency-price of water would result in inefficient consumption, since conservation investments reduce water scarcity and lower the efficiency price of groundwater. Moreover, volumetric surcharges may be insufficient to finance substantial startup costs when large conservation projects are considered. Instead, watershed conservation surcharges to groundwater users should be lump sum (e.g. via block pricing) and bond-financing may be needed to ensure a balanced intergenerational budget. Revenue from a proportional benefit tax can be used to pay off the bond without distorting incentives, and investment costs can be assigned in accordance with benefits. However, such a plan may require enabling legislation for water utilities to change their principles of finance. It is not uncommon that a utility is allowed to finance the construction and maintenance of infrastructure with water pricing but not the maintenance of nature's infrastructure that recharges the aquifer.

The theoretical framework developed is applicable to other instances of an upstream watershed providing ecosystem services downstream. For example, a decline in watershed quality increases runoff, which in turn creates more sediment flow. As the stock of sediment builds over time, the capacity of downstream reservoirs declines, and the power-generating capacity of hydroelectric plants also declines. In this case, watershed conservation should occur until the marginal costs of investment are equal to the marginal benefits, which are measured as the value of electricity capacity saved by the reduction in sediment flow. Assuming the utility generates its electricity primarily from the hydroelectric plant, a lump-sum tax scheme can be implemented to distribute watershed project costs in accordance with benefits obtained by electricity users. 
While the case discussed in the current paper involves a downstream water authority acting on behalf of its customers, other types of watershed conservation programs have been proposed. In the Philippines, for example, water users have organized to pay upland watershed users directly for conservation (WWF, 2009). Another example is the idea of equitable payments for watershed services, which has emerged recently as a market-based tool to induce efficient watershed management practices. For many of these proposed programs, our model can be used as a basis for calculating the efficient level of conservation and how much the water users should pay over what time period.

The analysis is a first step toward the optimal management of a groundwater aquifer and its associated watershed. Many simplifying assumptions are made to facilitate clearer understanding of the model's outcomes and resulting policy implications. Consequently, many possible research extensions could improve on and extend the basic model. Inasmuch as water balance, and hence groundwater infiltration, depends on many factors other than precipitation and forest stock (e.g. type of land cover, soil porosity, ground slope), the characterization of the state of the watershed should depend on vector of these factors in a real world application. In addition, these factors also vary over space, which means that implementation of a spatial version of the model would require detailed information provided, for example, by geographic information systems. While the data requirements for a spatial-temporal numerical application of the model are likely to be very high, the benefits may be substantial both in terms of informing policy with regard to the particular situation, as well as establishing an operational framework that is transferable to other regions once the necessary data inputs are identified and collected. 
Once operational, the spatial-temporal optimization model could be extended even further to include stochastic water balance elements and explicit time lags. Our framework can also be used to evaluate projects and policies that indirectly involve water scarcity. For example, subsidies for renewable energy might promote the use of waterintensive biofuel crops, which would increase the demand for groundwater, while simultaneously reducing available resources for public project-based forest conservation. As previously mentioned, our analysis focuses on the consumption benefits of enhanced groundwater recharge. A more advanced framework might take into account other flows of benefits generated by the watershed, such as reduced sedimentation, improved biodiversity, and increased cultural value.

\section{References}

Backhaus, J.G., Wagner, R.E., 2004. Handbook of Public Finance. Kluwer Academic Publishers, Boston, Dordrecht, New York, London.

Ballard, C.L., Shoven, J.B., Whalley, J., 1985. General Equilibrium Computations of the Marginal Welfare Costs of Taxes in the United States. The American Economic Review 75(1), 128-138.

Barbier, E.B., 2007. Valuing ecosystem services as productive inputs. Economic Policy, January 2007, 177-229.

Barbier, E.B., Strand, I., Sathirathai, S., 2002. Do Open Access Conditions Affect the Valuation of an Externality? Estimating the Welfare Effects of Mangrove-Fishery Linkages in Thailand. Environmental and Resource Economics 21, 343-367. 
Batabyal, A.A., Kahn, J.R., O’Neill, R.V., 2003. On the scarcity value of ecosystem services. Journal of Environmental Economics and Management 46, 334-352.

Baumol, W.J., Oates, W.E., 1988. The Theory of Environmental Policy, second ed. Cambridge University Press, Cambridge.

Carpenter, S.R., Mooney, H.A., Agard, J., Capistrano, D., DeFries, R.S., Diaz, S., Dietz, T., Duraiappah, A.K., Oteng-Yeboah, A., Pereira, H.M., Perrings, C., Reid, W.V., Sarukhan, J., Scholes, R.J., Whyte, A., 2009. Science for managing ecosystem services: Beyond the Millennium Ecosystem Assessment. Proceedings of the National Academy of Sciences 106(5), 1305-1312.

Conrad, J.M., Clark, C.W., 1987. Natural resource economics: Notes and problems. Cambridge University Press, New York.

Costanza, R., d'Arge, R., de Groot, R., Farber, S., Grasso, M., Hannon, B., Limburg, K., Naeem, S., O’Neil, R.V., Paruelo, J., Raskin, R.G., Sutton, P., van den Belt, M., 1997. The Value of the World's Ecosystem Services and Natural Capital. Nature 387(15), 253-260.

Daily, G.C., 1997. Nature's Services: Societal Dependence on Natural Ecosystems. Island Press, Washington, DC.

Daily, G.C., Söderqvist, T., Aniyar, S., Arrow, K., Dasgupta, P., Ehrlich, P.R., Folke, C., Jansson, A., Jansson, B., Kautsky, N., Levin, S., Lubchenco, J., Mäler, K., Simpson, D., Starrett, D., Tilman, D., Walker, B., 2000. The Value of Nature and the Nature of Value. Science 289(5478), 395-396.

Daily, G.C., Polasky, S., Goldstein, J., Kareiva, P.M., Mooney, H.A., Pejchar, L., Ricketts, T.H., Salzman, J., Shallenberger, R., 2009. Ecosystem services in 
decision making: time to deliver. Frontiers in Ecology and the Environment 7(1), 21-28.

Dasgupta, P., 2001. Human Well-being and the Natural Environment. Oxford Univeristy Press, Oxford.

Dasgupta, P., 2009. The Welfare Economic Theory of Green National Accounts. Environmental and Resource Economics 42(1), 3-38.

Debreu, G., Scarf, H., 1963. A Limit Theorem on the Core of an Economy. International Economic Review 4(3), 235-246.

Dixit, A., 2004. Lawlessness and Economics: Alternative Modes of Governance. Princeton University Press, Princeton, NJ.

Engel, S., Pagiola, S., Wunder, S., 2008. Designing payments for environmental services in theory and practice: An overview of the issues. Ecological Economics 65, 663674.

Farber, S.C., Costanza, R., Wilson, M.A., 2002. Economic and ecological concepts for valuing ecosystem services. Ecological Economics 41, 375-392.

Feinerman, E., Knapp, K.C., 1983. Benefits from Groundwater Management: Magnitude, Sensitivity, and Distribution. American Journal of Agricultural Economics 65, 703-710.

Ferrarro, P.J., Simpson, R.D., 2002. The Cost-Effectiveness of Conservation Payments. Land Economics 78(3), 339-353.

Gisser, N., Sanchez, D.A., 1980. Competition Versus Optimal Control in Groundwater Pumping. Water Resources Research 31, 638-642.

Hines, J.R., 2000. What is benefit taxation? Journal of Public Economics 75, 483-492. 
IPCC, 2007a. Climate Change 2007: The Physical Science Basis. Contribution of Working Group I to the Fourth Assessment Report of the Intergovernmental Panel on Climate Change. Solomon, S., Qin, D., Manning, M., Chen, Z., Marquis, M., Averyt, K.B., Tignor, M., Miller, H.L. (Eds.), Cambridge University Press, Cambridge.

IPCC. 2007b. Climate Change 2007: Impacts, Adaptation and Vulnerability. Contribution of Working Group II to the Fourth Assessment Report of the Intergovernmental Panel on Climate Change. Parry, M.L., Canziani, O.F., Palutikof, J.P., van der Linden P.J., Hanson, C.E. (Eds.), Cambridge University Press, Cambridge.

Jorgensen, D.W., 1963. Capital Theory and Investment Behavior. The American Economic Review 53(2), 247-259.

Kaiser, B., Roumasset, J., 2002. Valuing Indirect Ecosystem Services: the Case of Tropical Watersheds. Environment and Development Economics 7, 701-714. Kareiva, P., Tallis, H., Ricketts, T.H., Daily, G.C., Polasky, S. (Eds.), 2011. Natural Capital: Theory and Practice of Mapping Ecosystem Services. Oxford University Press, New York.

Koundouri, P., 2004. Current Issues in the Economics of Groundwater Resource Management. Journal of Economic Surveys 18, 703-738.

Koundouri, P., Christou, C., 2006. Dynamic adaptation to resource scarcity and backstop availability: theory and application to groundwater. The Australian Journal of Agricultural and Resource Economics 50, 227-245. 
Krulce, D., Roumasset, J., Wilson, T., 1997. Optimal Management of a Renewable and Replaceable Resource: the Case of Coastal Groundwater. American Journal of Agricultural Economics 79, 1218-1228.

Libecap, G.D., 1989. Contracting for Property Rights. Cambridge University Press, Cambridge.

Lindahl, E., 1958. Just taxation - A positive solution, Henderson, E. (Trans.), in:

Musgrave, R.A., Peacock, A.T. (Eds.), Classics in the Theory of Public Finance. Macmillan, London.

Liu, J., Li, S., Ouyang, Z., Tam, C., Chen, X., 2008. Ecological and socieoeconomic effects of China's policies for ecosystem services. Proceedings of the National Academy of Sciences 105, 9477-9482.

Mann, P.C., Clark, D.M., 1993. Marginal-Cost Pricing: Its Role in Conservation. Journal of the American Water Works Association 85(8), 71-78.

Mendoza, G., Ennaanay, D., Conte, M., Walter, M.T., Freyberg, D., Wolny, S., Hay, L., White, S., Nelson, E., Solorzano, L., 2011. Water supply as an ecosystem service for hydropower and irrigation, in Kareiva, P., Tallis, H., Ricketts, T.H., Daily, G.C., Polasky, S. (Eds.), Natural Capital: Theory and Practice of Mapping Ecosystem Services. Oxford University Press, New York, pp. 53-72.

Millennium Ecosystem Assessment, 2005. Ecosystems and human well-being: the assessment series. Island Press, Washington, D.C.

Mink, J.F., 1980. State of the Groundwater Resources of Southern Oahu. Honolulu Board of Water Supply, Honolulu, HI. 
Muñoz-Piña, C., Guevara, A., Torres, J. M., Braña, J., 2008. Paying for the hydrological services of Mexico's forests: Analysis, negotiations and results. Ecological Economics 65, 725-736.

Nechyba, T., 2010. Microeconomics: An Intuitive Approach With Calculus. SouthWestern, Cengage Learning.

Pagiola, S., Arcenas, A., Platais, G., 2005. Can payments for environmental services help reduce poverty? An exploration of the issues and the evidence to date from Latin America. World Development 33, 237-253.

Pagiola, S., 2008. Payments for environmental services in Costa Rica. Ecological Economics 65, 712-724.

Pearce, D.W., 2001. The Economic Value of Forest Ecosystems. Ecosystem Health 7(4), 284-296.

Pitafi, B.A., Roumasset, J.A., 2003. Efficient groundwater pricing and watershed conservation finance: the Honolulu case. Paper prepared for the American Agricultural Economics Association Annual Meeting, Montreal, Canada, July 2730, 2003.

Pitafi, B.A., and J.A. Roumasset. 2006. "Evaluating Interdependent Watershed Conservation and Groundwater Management Reforms." Journal of the American Water Resources Association 42:1441-1450.

Pitafi, B.A., Roumasset, J.A., 2009. Pareto-Improving Water Management Over Space and Time: The Honolulu Case. American Journal of Agricultural Economics 91, 138-153. 
Rodini, M., Ward, M.R., Woroch, G.A., 2003. Going mobile: substitutability between fixed and mobile access. Telecommunications Policy 27, 457-476.

Roumasset, J., Burnett, K., Balisacan, A.M. (Eds.), 2010. Sustainability Science for Watershed Landscapes. Institute of Southeast Asian Studies, Singapore; Southeast Asian Regional Center for Graduate Study and Research in Agriculture, Los Baños, Philippines.

Sanchirico, J.N., Springborn, M., 2011. How to Get There From Here: Ecological and Economic Dynamics of Ecosystem Service Provision. Environmental and Resource Economics 48, 243-267.

Shapley, L.S., 1953. A Value for N-Person Games, in Kuhn, H.W., Tucker, A.W. (Eds.), Contributions to the Theory of Games Vol. 2. Princeton University Press, New Jersey, pp. 307-317.

Shughart, W.F., Razzolini, L., 2003. The Elgar Companion to Public Choice. Edward Elgar Publishing, Inc., Massachusetts.

Sathirathai, S. Barbier, E.B., 2001. Valuing Mangrove Conservation in Southern Thailand. Contemporary Economic Policy 19(2), 109-122.

Stiglitz, J., Sen, A., Fitoussi, J., 2010. Mismeasuring our Lives. The New Press, New York.

Turner, R.K., Daily, G.C., 2008. The Ecosystem Services Framework and Natural Capital Conservation. Environmental and Resource Economics 39, 25-35.

Weitzman, M.L., 1997. Sustainability and Technical Progress. Scandinavian Journal of Economics 99(1), 1-13. 
Wicksell, K., 1958. A New Principle of Just Taxation, in: Musgrave, R.A., Peacock, A.T. (Eds.), Classics in the Theory of Public Finance. St. Martin's, New York.

World Bank Global Climate Change Team, Mathur, A., Burton, I., van Aalst, M. (Eds.), 2004. An Adaptation Mosaic: A Sample of the Emerging World Bank Work in Climate Change Adaptation.

World Water Assessment Programme (WWAP), 2009. The United Nations World Water Development Report 3: Water in a Changing World. Earthscan, London.

World Wildlife Fund (WWF), 2009. WWF Office \& Associates: Philippines: Ilagan Watershed Conservation Project. Accessed online August 6, 2010: http://wwf.panda.org/who_we are/wwf_offices/philippines/index.cfm?uProjectID $\underline{=\mathrm{PH} 0958}$ 